\title{
The Regulation of Xanthine Oxidase
}

\section{INHIBITION BY REDUCED NICOTINAMIDE-ADENINE DINUCLEOTIDE OF RAT LIVER XANTHINE OXIDASE TYPE D AND OF CHICK LIVER XANTHINE DEHYDROGENASE}

\author{
By E. DELLA CORTE AND F. STIRPE \\ Istituto di Patologia generale dell'Università di Bologna, 40126 Bologna, Italy
}

(Received 6 October 1969)

\begin{abstract}
1. Rat liver xanthine oxidase type $\mathrm{D}\left(\mathrm{NAD}^{+}\right.$-dependent) and chick liver xanthine oxidase are inhibited by $\mathrm{NADH}$, which competes with $\mathrm{NAD}^{+} .2$. The addition of a NADH-reoxidizing system in the assay of these enzyme activities is proposed. 3. Rat liver xanthine oxidase type $\mathrm{O}$ (oxygen-dependent) is not affected by NADH.
\end{abstract}

The oxidation of hypoxanthine to xanthine and of xanthine to uric acid is catalysed by xanthine oxidase (EC 1.2.3.2). This enzyme has been considered to be an oxidase in mammalian organs (De Renzo, 1956), whereas it is a dehydrogenase in the organs of birds, with $\mathrm{NAD}^{+}$probably being the physiological electron acceptor (Morell, 1955a,b; Fellig \& Wiley, 1958). We have reported that in freshly prepared supernatant from rat liver the conversion of xanthine into uric acid occurs only to a limited extent through an oxidase reaction, and about five times as rapidly through a $\mathrm{NAD}^{+}$. dependent dehydrogenation. The rate of the dehydrogenase reaction decreased and that of the oxidase increased if the supernatant was submitted to a variety of treatments, such as keeping it at $-20^{\circ} \mathrm{C}$ for some hours (Della Corte \& Stirpe, 1968a), preincubating it with proteolytic enzymes (Della Corte \& Stirpe, 1968b) or with any particulate subcellular fraction, or keeping it under anaerobic conditions (Stirpe \& Della Corte, 1969). The effects of proteolytic enzymes and of anaerobiosis were accelerated by the presence of xanthine. Similar observations were made with human liver (Della Corte, Gozzetti, Novello \& Stirpe, 1969), whereas in all other rat organs examined the reaction appeared to be entirely an oxidase (Stirpe \& Della Corte, 1969). On the basis of these results, it was postulated that in the liver of rat and man, and presumably of other mammals, the xanthine 'oxidase' may exist in two interconvertible forms: an oxidase, type $O$, and a dehydrogenase, type $D$. The fact that in one case at least the conversion of type $\mathrm{D}$ into type $\mathrm{O}$ is reversible allows one to suppose that the interconversion between the two types may occur under physiological conditions, and may possibly play a role in the regulation of xanthine oxidase activity.

We report in this paper that the xanthine oxidase (type D) of rat liver and the xanthine dehydrogenase of chick liver are inhibited by NADH, in a manner competitive with $\mathrm{NAD}^{+}$. Besides having practical implications for the correct assay of the enzyme activity and for the study of its properties, the results obtained may clarify some aspects of the regulation of xanthine oxidation in mammals and birds.

\section{EXPERIMENTAL}

Chemicals. Xanthine (monosodium salt) was purchased from Nutritional Biochemicals Corporation, Cleveland, Ohio, U.S.A.; $\mathrm{NAD}^{+}, \mathrm{NADH}, \mathrm{NADP}^{+}, \mathrm{NADPH}$, trypsin (type XI) and lactate dehydrogenase (type II) were from Sigma Chemical Co., St Louis, Mo., U.S.A.; sodium pyruvate was from E. Merck A.-G., Darmstadt, Germany. All other chemicals were of analytical grade.

Enzyme preparations. Livers from normal Wistar rats weighing about $150-200 \mathrm{~g}$ or from 10-day-old chicks were homogenized in $0.1 \mathrm{M}$-tris-HCl buffer, $\mathrm{pH} 8.1$ (1 $\mathrm{g}$ of liver+ $5 \mathrm{ml}$ of buffer). The homogenate from rat liver was centrifuged at $800-900 \mathrm{~g}$ for $20 \mathrm{~min}$ at $0^{\circ} \mathrm{C}$, and the supernatant was centrifuged again at $100000 \mathrm{~g}$ for $1 \mathrm{~h}$ in a Spinco-Beckman L2/65K or MSE 40 centrifuge. The supernatant was dialysed for at least $3 \mathrm{~h}$ against a continuous flow of $300 \mathrm{vol}$. of the tris buffer. The supernatant was used as such for the enzyme determinations, since the attempt to purify xanthine oxidase from rat liver converted the enzyme from type $\mathrm{D}$ into type 0 . The supernatant could be stored at $0^{\circ} \mathrm{C}$ for $5-7$ days without loss of activity or conversion of type $D$ into type $0:$ after 1-2 days some material was precipitated, which could be centrifuged off without change in the enzymic activity. Rat liver xanthine oxidase was activated by preincubating the supernatant at $37^{\circ} \mathrm{C}$ for $1 \mathrm{~h}$ in the presence of trypsin $(100 \mu \mathrm{g} / \mathrm{ml})$ and $\mathrm{mM}$-xanthine. The supernatant was dialysed before the assay.

The homogenate from chick liver was centrifuged at $100000 \mathrm{~g}$ for $1 \mathrm{~h}$, the supernatant was made $35 \%$ saturated with respect to $\left(\mathrm{NH}_{4}\right)_{2} \mathrm{SO}_{4}$, and the precipitated material was removed by centrifugation. The supernatant was made $55 \%$ saturated with respect to $\left(\mathrm{NH}_{4}\right)_{2} \mathrm{SO}_{4}$ and

Bioch. 1970, 117 
centrifuged again. 'The supernatant was discarded and the sediment was dissolved in the tris buffer $(1 \mathrm{ml}$ per $5 \mathrm{ml}$ of $100000 \mathrm{~g}$ supernatant). The preparation was stored at $0^{\circ} \mathrm{C}$ for a few days, or at $-20^{\circ} \mathrm{C}$ for longer periods.

Assay of xanthine oxidase and xanthine dehydrogenase. The oxidase activity (type 0 ) of rat liver supernatant was assayed by the method of Rowe \& Wyngaarden (1966) as described by Stirpe \& Della Corte (1969). The NAD ${ }^{+}$. dependent activity (type D) was determined by measuring the amount of uric acid formed aerobically in the presence of $\mathrm{NAD}^{+}$and by subtraction of the oxidase activity.

The chick liver enzyme was assayed essentially as described by Strittmatter (1965), except that $0.1 \mathrm{M}$-trisHCl buffer, pH8.1, was substituted for phosphate buffer, and EDTA was omitted. Initial rates were measured in all experiments.

$K_{m}$ values were calculated by plotting $s / v$ against $s$ (Hanes, 1932), where $s$ is the substrate concentration and $v$ is the velocity. Lines were fitted by the least-squares method; $K_{t}$ values were calculated from the formula given by Dixon \& Webb (1964) for competitive inhibitors.

\section{RESULTS}

Inhibition by NADH of rat liver xanthine oxidase (type D) and chick liver xanthine dehydrogenase. During the assay of rat liver xanthine oxidase (type D), it was observed that the reaction rate in the presence of $\mathrm{NAD}^{+}$decreased shortly after the beginning of the reaction. This occurred too rapidly

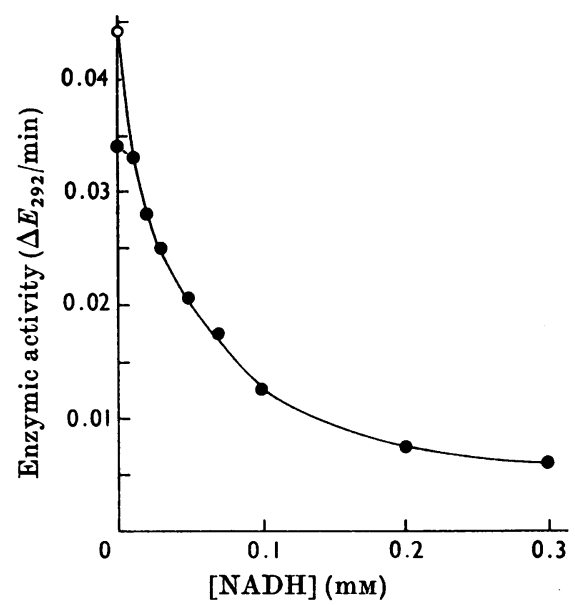

Fig. 1. Inhibition by NADH of rat liver xanthine oxidase (type D). The enzyme activity was determined as described in the Experimental section. The reaction mixture contained, in a final volume of $3 \mathrm{ml}, 0.1 \mathrm{M}$-tris$\mathrm{HCl}$ buffer, $\mathrm{pH} 8.1,60 \mu \mathrm{M}$-xanthine, $0.5 \mathrm{~mm}-\mathrm{NAD}^{+}$, the appropriate amount of $\mathrm{NADH}$ and $0.2 \mathrm{ml}$ of rat liver supernatant. Determinations without NADH were performed with (O) and without $(\bullet)$ addition of sodium pyruvate $(5 \mu \mathrm{mol})$ and lactate dehydrogenase $(10 \mu \mathrm{l}$ of a 1:10 dilution of the enzyme). to be due to lack of substrates, and inhibition by the uric acid formed was unlikely, since the reaction rate did not decline in the assays of the xanthine oxidase (type $\mathrm{O}$ ). When pyruvate and lactate dehydrogenase were added to the reaction mixtures to remove the NADH produced by the reaction (Stirpe \& Della Corte, 1969), the declining reaction accelerated and proceeded at the initial or even at a faster rate until the substrate was consumed. This suggested that the NADH produced was inhibiting the reaction, and this was proved by adding NADH to the assay mixtures (Fig. 1). In the presence of pyruvate and lactate dehydrogenase the enzymic activity at various concentrations of $\mathrm{NAD}^{+}$gave a Michaelis-Menten type of curve, the $K_{m}$ for $\mathrm{NAD}^{+}$ being $2.24 \times 10^{-5} \mathrm{M}$. NADH added in the absence of pyruvate and lactate dehydrogenase inhibited the reaction, by competing with $\mathrm{NAD}^{+}$(Fig. 2). Experiments performed at various concentrations of xanthine demonstrated that NADH did not compete with this substrate (Fig. 3). The xanthine oxidase (type $\mathrm{O}$ ) activity of fresh supernatant or of trypsin-treated supernatant was not affected by NADH or by the addition of pyruvate and lactate dehydrogenase. NADPH did not affect the type D reaction, and $\mathrm{NADP}^{+}$did not substitute for $\mathrm{NAD}^{+}$ as acceptor.

Similar experiments were performed with chick liver preparations and in this case also inhibition by NADH was observed that was competitive for $\mathrm{NAD}^{+}$and not for xanthine. The constants for rat liver and chick liver enzymes are summarized in Table 1. Compared with chick liver xanthine dehydrogenase, the rat liver enzyme had a lower $K_{m}$ for xanthine, a higher $K_{m}$ for $\mathrm{NAD}^{+}$and a similar $K_{\imath}$ for inhibitory NADH.

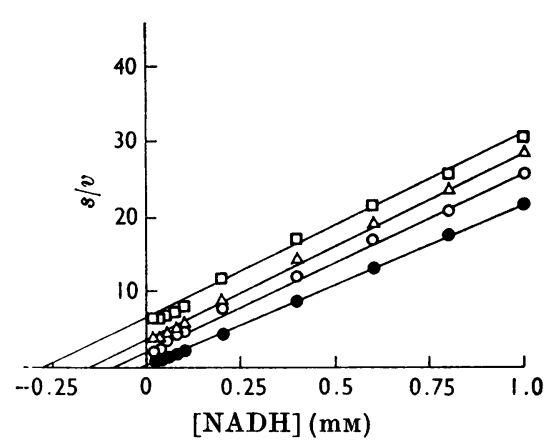

Fig. 2. Inhibition by NADH of rat liver xanthine oxidase (type D) at fixed xanthine concentration. Experimental conditions were as in Fig. 1 except for the concentration of $\mathrm{NAD}^{+}$. Sodium pyruvate and lactate dehydrogenase were added to all samples without NADH. $\bullet$, No NADH added; $O, \quad 0.01 \mathrm{~mm}-\mathrm{NADH} ; \triangle, \quad 0.02 \mathrm{~mm}-\mathrm{NADH} ; \square$, $0.03 \mathrm{~mm}-\mathrm{NADH}$. 
Determination of xanthine dehydrogenase. The results reported above allowed selection of the proper experimental conditions for the assay of xanthine oxidase (type D) from rat liver and of xanthine dehydrogenase from chick liver. In either case addition of pyruvate and of lactate dehydrogenase removed the NADH formed, thus preventing inhibition of the enzyme. The rat liver type $D$ enzyme could be determined aerobically, provided that the type $O$ enzyme was determined separately, and the values subtracted from those obtained in the presence of $\mathrm{NAD}^{+}$. If pyruvate and lactate dehydrogenase were added, the formation of uric acid was directly proportional to the quantity of supernatant used up to $0.2-0.25 \mathrm{ml}$ (Fig. 4).

\section{DISCUSSION}

The xanthine oxidase (type D) from rat liver and the xanthine dehydrogenase from chick liver are

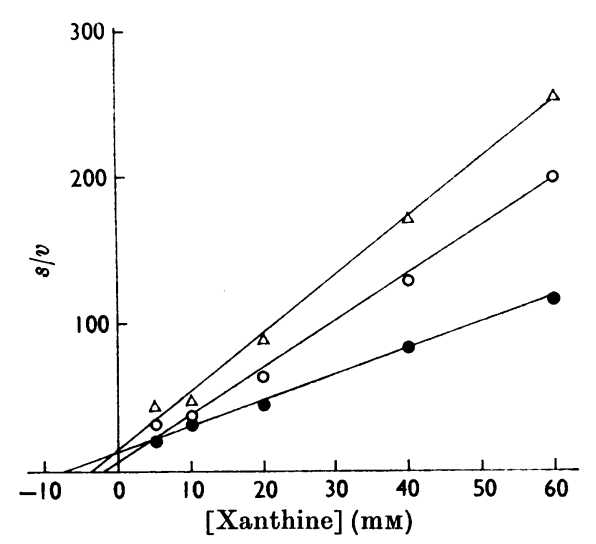

Fig. 3. Inhibition by $\mathrm{NADH}$ of rat liver xanthine oxidase (type D) at fixed $\mathrm{NAD}^{+}$concentration $(0.8 \mathrm{~mm})$. Experimental conditions were as in Figs. 1 and 2. $\bullet$, No NADH added; O, $0.03 \mathrm{~mm}-\mathrm{NADH} ; \triangle, 0.06 \mathrm{~mm}-\mathrm{NADH}$. inhibited by $\mathrm{NADH}$, which competes for $\mathrm{NAD}^{+}$in both cases. This inhibition accounts for the stimulating effect of pyruvate observed with the chick liver enzyme by Morell $(1955 a, b)$ and by Landon \& Carter (1960). It may also explain why the $K_{m}$ for $\mathrm{NAD}^{+}$of the chick liver xanthine dehydrogenase observed in our experiments is about one-tenth of the values reported by Landon \& Carter (1960), by Strittmatter (1965) and by Rajagopalan \& Handler (1967) on the basis of experiments that might have been affected by the NADH formed during the dehydrogenation of xanthine. Inhibition by NADH of the $\mathrm{NAD}^{+}$-dependent chick liver xanthine dehydrogenase was observed by Landon \& Carter (1960), who reported that the inhibition could not

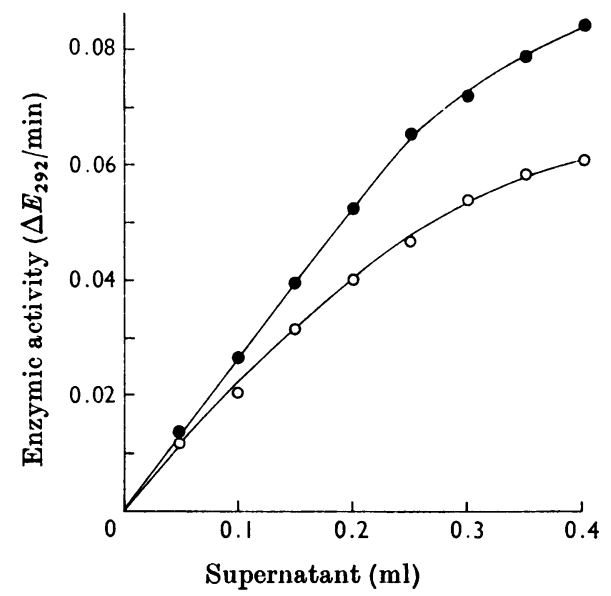

Fig. 4. Determination of the activity of rat liver xanthine dehydrogenase (type D) with (०) and without (O) sodium pyruvate and lactate dehydrogenase. Experimental conditions were as in Fig. 1 except that the concn. of $\mathrm{NAD}^{+}$was $0.7 \mathrm{~mm}$.

Table 1. Kinetic constants of rat liver xanthine oxidase and of chick liver xanthine dehydrogenase

Experimental conditions were as described in the Experimental section.

\begin{tabular}{|c|c|c|c|c|c|}
\hline Enzyme & Acceptor & $\begin{array}{c}\text { Final concn. } \\
\text { of NADH added } \\
(\mu \mathrm{M})\end{array}$ & $\begin{array}{c}10^{6} \times K_{m} \\
\text { (xanthine) } \\
(\mathrm{M})\end{array}$ & $\begin{array}{c}10^{6} \times K_{m} \\
\left(\mathrm{NAD}^{+}\right) \\
(\mathrm{M})\end{array}$ & $\begin{array}{c}10^{6} \times K_{l} \\
(\mathrm{NADH} \\
(\mathrm{M})\end{array}$ \\
\hline \multicolumn{6}{|l|}{ Rat liver } \\
\hline Type $O$ (native) & $\mathrm{O}_{2}$ (air) & - & 2.14 & - & - \\
\hline \multirow[t]{3}{*}{ Type O (activated) } & & - & 7.58 & - & - \\
\hline & & 一 & 7.13 & 22.4 & - \\
\hline & & 10 & - & 100 & 2.9 \\
\hline \multirow[t]{4}{*}{ Type D } & $\mathrm{NAD}^{+}$ & 20 & - & 141 & 3.8 \\
\hline & & 30 & 2.86 & 285 & 2.6 \\
\hline & & 60 & 3.73 & - & 一 \\
\hline & & - & 22.8 & 3.10 & - \\
\hline \multirow[t]{2}{*}{ Chick liver } & $\mathrm{NAD}^{+}$ & $\{30$ & 16.5 & 28.2 & 3.7 \\
\hline & & 60 & 14.4 & 35.5 & 5.7 \\
\hline
\end{tabular}


be abolished by excess of $\mathrm{NAD}^{+}$, although it was abolished by pyruvate and lactate dehydrogenase. These authors concluded that pyruvate and lactate dehydrogenase acted by reoxidizing NADH bound to the enzyme.

The fact that NADH does not compete with xanthine and does not affect the type $O$ enzyme suggests that $\mathrm{NAD}^{+}$and xanthine bind at different sites on rat liver xanthine oxidase (type D) and on chick liver xanthine dehydrogenase. NADH may act as substrate for xanthine oxidase from various sources [milk (Corran, Dewan, Gordon \& Green, 1939; Mackler, Mahler \& Green, 1954); calf liver (Kielley, 1955); avian kidney (Landon \& Myles, 1967); chick liver (Rajagopalan \& Handler, 1967)], and Mackler et al. (1954) and Kielley (1955) concluded that it must bind at a site different from that for xanthine. Rajagopalan \& Handler (1967) reported that $\mathrm{NAD}^{+}$and $\mathrm{NADH}$ share a common binding site on chick liver xanthine dehydrogenase. Thus the hypothesis may be formulated that the type D enzyme from rat liver, as well as the chick liver dehydrogenase, has two binding sites, one for xanthine and one for $\mathrm{NAD}^{+}$or NADH, and that xanthine is dehydrogenated at the xanthine site and the hydrogen is transferred to $\mathrm{NAD}^{+}$bound to the other site and then to a suitable acceptor.

The constants of rat liver xanthine oxidase (type D) demonstrate that the rat liver enzyme has a higher affinity for xanthine and a lower affinity for $\mathrm{NAD}^{+}$than those of chick liver xanthine dehydrogenase. This is consistent with the metabolic situation in which the two enzymes operate. The greater affinity of the rat liver enzyme for xanthine agrees with the lesser availability of this substrate in mammals as compared with uricotelic birds. One would also expect the chick liver enzyme to have a higher affinity for $\mathrm{NAD}^{+}$than the rat liver enzyme, since the latter (i) has a lower load of substrate and (ii) may be converted into an oxidase (assuming that type $\mathrm{O}$ enzyme exists in vivo), thus becoming in part independent of $\mathrm{NAD}^{+}$, whereas in chick liver the enzyme is a dehydrogenase, and must rely entirely on $\mathrm{NAD}^{+}$for its functioning. The great sensitivity of the rat liver xanthine oxidase (type D) to inhibition by NADH allows the possibility that the activity of this enzyme is modulated by the $\mathrm{NAD}^{+}$/ NADH concentration ratio in the liver.

We thank Professor E. Bonetti for his interest in this research. The work was aided by a grant from Consiglio Nazionale delle Ricerche, Rome.

\section{REFERENCES}

Corran, H. S., Dewan, J. G., Gordon, A. H. \& Green, D. E. (1939). Biochem.J. 33, 1694.

Della Corte, E., Gozzetti, G., Novello, F. \& Stirpe, F. (1969). Biochim. biophys. Acta, 191, 164.

Della Corte, E. \& Stirpe, F. (1968a). Biochem. J. 108, 427. Della Corte, E. \& Stirpe, F. (1968b). FE BS Lett. $2,83$.

De Renzo, E. C. (1956). Adv. Enzymol. 17, 293.

Dixon, M. \& Webb, E. C. (1964). Enzymes, 2nd ed., p. 328. London: Longmans, Green and Co. Ltd.

Fellig, J. \& Wiley, C. E. (1958). Nature, Lond., 181, 51. Hanes, C. S. (1932). Biochem. J. 26, 1406.

Kielley, R. K. (1955). J. biol. Chem. 216, 405.

Landon, E. J. \& Carter, C. E. (1960). J. biol. Chem. 235, 819.

Landon, E. J. \& Myles, M. (1967). Biochim. biophys. Acta, $143,429$.

Mackler, B., Mahler, H. R. \& Green, D. E. (1954). J. biol. Chem. 210, 149.

Morell, D. B. (1955a). Biochim. biophys. Acta, 16, 258. Morell, D. B. (1955b). Biochim. biophys. Acta, 18, 221.

Rajagopalan, K. V. \& Handler, P. (1967). J. biol. Chem. 242, 4097.

Rowe, P. B. \& Wyngaarden, J. B. (1966). J. biol. Chem. 241,5571

Stirpe, F. \& Della Corte, E. (1969). J. biol. Chem. 244, 3855 .

Strittmatter, C. (1965). J. biol. Chem. 240, 2557. 